\title{
Alanine Aminotransferase Activity in Hypothyroid Patients: A Cross Sectional Study
}

\author{
Md. Aminul Haque Khan \\ Md. Rezwanur Rahman ${ }^{2}$ \\ Rawnak Jahan ${ }^{3}$ \\ 'Department of Biochemistry \\ Enam Medical College, Savar \\ Dhaka, Bangladesh. \\ ${ }^{2}$ Department of Biochemistry \\ Delta Medical College \\ Dhaka, Bangladesh.
}

${ }^{3}$ Department of Clinical Biochemistry Bangladesh Institute of Health Sciences Dhaka, Bangladesh.

*Correspondence to:

Md. Aminul Haque Khan Department of Biochemistry Enam Medical College, Savar Dhaka, Bangladesh.

Mobile: +880-1552479546

E-mail:aminhkhan@yahoo.com

\begin{abstract}
Background: Hypothyroidism is associated with many biochemical abnormalities including increased serum alanine aminotransferase activity. Very few studies have been done regarding serum alanine aminotransferase activity in hypothyroid patients and, as far we know, no such study has been done in our populations. So, we designed this study in our population for evaluation of serum alanine aminotransferase activity in hypothyroid patients. The objective of this study was to assess serum alanine aminotransferase activity in hypothyroid patients and to find out relationship of alanine aminotransferase activity with severity of hypothyroidism. Methods: It was a retrospective cross sectional study to evaluate the serum alanine aminotransferase activity of hypothyroid patients and to find out relationship of alanine aminotransferase activity with severity of hypothyroidism and the values were compared with that of age and sex matched healthy euthyroid controls. Statistical analyses were performed by using SPSS for Windows version 12.0. Unpaired ' $t$ ' test was done to find out any significant difference between the cases and controls with respect to age and serum alanine aminotransferase activity. Chisquare test was done to find out any significant difference between the cases and controls with respect to sex. Pearson correlation coefficient test was done to see the correlation of alanine aminotransferase activity with the severity of hypothyroidism. Results: Mean serum alanine aminotransferase activity was found significantly higher in hypothyroid patients compared to that of controls. Conclusion: Results of our study suggest that increased serum alanine aminotransferase activity is associated with hypothyroidism. Therefore, patients presenting with increased ALT activity with normal liver function tests are recommended to be investigated to explore hypothyroidism.
\end{abstract}

Key words: Hypothyroidism; ALT activity; Metabolic derangement.

\section{INTRODUCTION}

Hypothyroidism is a clinical syndrome resulting from a deficiency of thyroid hormones, which in turn results in a generalized slowing down of metabolic processes $^{1}$. It is a common metabolic disorder in general population ${ }^{2}$. The thyroid dysfunction increases with age, especially in women ${ }^{3}$. The prevalence of primary hypothyroidism is $1: 100$, but it may be $5: 100$ if patients with subclinical hypothyroidism (normal $\mathrm{T}_{4}$, raised TSH) are included ${ }^{4}$. According to a study done by Sawin et $\mathrm{al}^{5}$. hypothyroidism is a common disorder with a prevalence rate up to $20 \%$. In another cross-sectional study on twelve hundred and twelve subjects of both sexes and age 20-60 years, the incidence of subclinical hypothyroidism was $19.7 \%{ }^{6}$. Hypothyroidism is associated with many biochemical abnormalities and so it is of paramount clinical importance to have proper knowledge of these abnormalities and accurate estimation of these biochemical parameters is very important and useful for clinical management of the patients. Very few studies have been done to assess serum alanine aminotransferase (ALT) activity of hypothyroid patients and as far we know, no such study has done in our populations. So, we designed this study in our population for evaluation of serum ALT activity in hypothyroid patients and that might be helpful for clinical management of hypothyroid patients with abnormal ALT activity. 


\section{MATERIALS AND METHODS}

This cross sectional study was carried out in the Department of Clinical Biochemistry, Bangladesh Institute of Health Sciences, Dhaka during the period J uly 2012 to J une 2013 to evaluate the serum ALT activity of hypothyroid patients and to find out relationship of ALT activity with severity of hypothyroidism and the values were compared with that of age and sex matched healthy euthyroid subjects. Clinically and biochemically newly diagnosed 80 hypothyroid patients of both sexes, age 20 to 60 years, with no history of thyroxine or any other medication that can influence thyroid hormone status and/or ALT activity in the last 3 (three) months were included in the study. Patients with chronic renal failure, diabetes mellitus, liver diseases, chronic diseases, pregnancy and age less than 20 and more than 60 years were excluded. Hypothyroidism was diagnosed by clinical history, physical examinations and relevant laboratory investigations. Total 146 subjects were included in the study and out of them 80 overt hypothyroid patients were grouped as cases and age and sex matched 66 euthyroid subjects were grouped as controls. Specimen was collected taking aseptic measures, allowed to clot, serum was separated and analyzed for A LT activity.

\section{Statistical analysis}

Statistical analyses were performed by using SPSS for Windows version 12.0. Mean values of the findings were compared between groups. U npaired ' $t$ ' test was done to see the significance between groups. Chi-square test was done to find out any difference with respect to sex distribution between cases and controls. Pearson correlation coefficient test was done to see the correlation of serum ALT activity with serum TSH and $\mathrm{FT}_{4}$ levels. ' $p$ ' values $<0.05$ were considered significant.

\section{RESULTS}

Table I shows the age distribution of study subjects and Table II shows the sex distribution. There was no significant difference between the cases and controls with respect to age and sex. Table III shows the comparison of the serum ALT levels between the cases and the controls. M ean serum ALT levels were found significantly increased in cases as compared to controls.

Table 1: A ge distribution of study subjects ( $N=146)$

$\begin{array}{llcc}\text { Study subjects } & \text { A ge in years } & \text { t value } & \text { ' } p \text { ' value } \\ \text { Cases }(n=80) & 32.66 \pm 10.19 & 0.449 & 0.654 \\ \text { Controls }(n=66) & 31.79 \pm 13.35 & & \end{array}$

Table 2: Distribution of study subjects by sex $(N=146)$

$\begin{array}{lcccc}\text { Study subjects } & \text { Male } & \text { Female } & \chi^{2} \text { value } & p \text { value } \\ \text { Cases }(n=80) & 13 & 67 & 0.992 & 0.229 \\ \text { Controls }(n=66) & 7 & 59 & & \end{array}$

Table 3: Comparison of serum A LT levels between cases and controls

$\begin{array}{lccc}\text { Study subjects } & \text { Serum ALT (U/L) } & \text { t value } & \text { ' } p \text { ' value } \\ \text { Cases }(n=80) & 36.53 \pm 18.72 & 2.921 & 0.004 \\ \text { Controls }(n=66) & 28.20 \pm 15.01 & & \end{array}$

Fig 1 show s correlation of serum ALT levels with serum TSH levels, serum ALT levels correlate positively with serum TSH levels ( $r=0.192 ; p=0.036$ ). Fig 2 shows correlation of serum ALT levels with serum free thyroxine level, serum ALT level correlates negatively with serum $\mathrm{FT}_{4}$ levels ( $r=-0.211$, $p=0.021$ ).

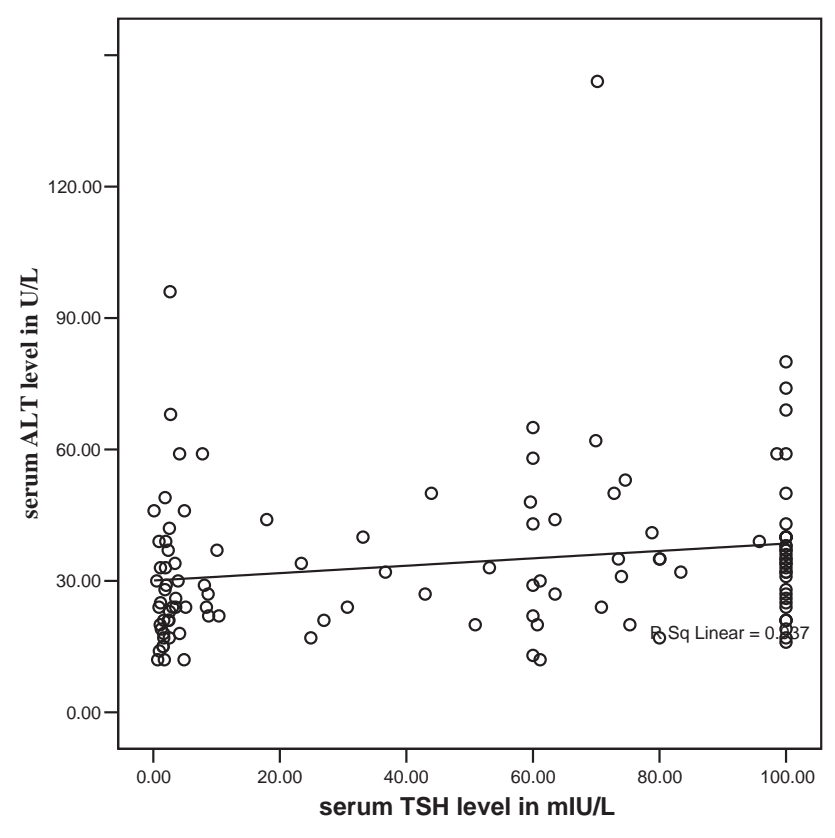

Figure 1 : Correlation of serum A LT levels with serum TSH levels

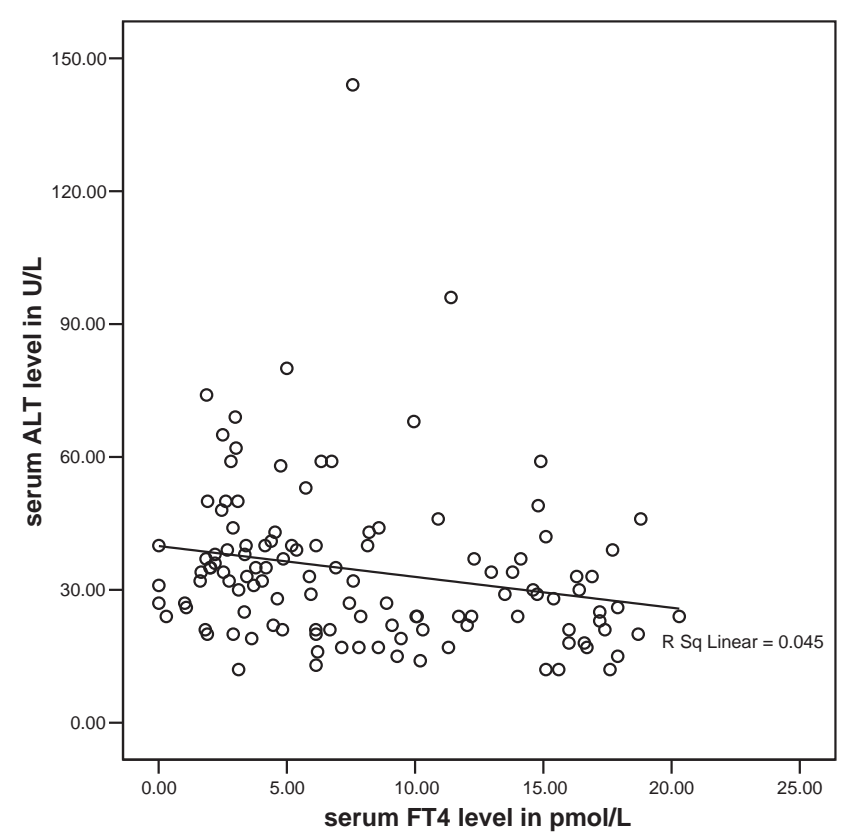

Figure 2 : Correlation of serum ALT levels with serum $\mathrm{FT}_{4}$ levels 


\section{DISCUSSION}

In this study, mean serum ALT levels in cases were found significantly higher than in the control subjects. This finding is consistent with the previous studies done by other investigators $^{7-10}$. Mean serum ALT level in a hypothyroid case was found significantly greater in comparison to euthyroid value in a study done by 0 hkubo et $\mathrm{al}^{7}$. In this study researchers reported a case of a 2-year-old male child with ring chromosome 18 who developed hypothyroidism and liver dysfunction. Transaminase level became normal after he was given levothyroxine therapy to achieve the euthyroid state, but repeatedly became elevated when levothyroxine was inadvertently discontinued. A maintenance dose of levothyroxine has effectively maintained the euthyroid state and normalized liver function tests despite no immunosuppressive therapy. In another study Targher et $\mathrm{al}^{8}$ found hypothyroidism associated with slightly increased serum A LT activity. Goncales et $\mathrm{al}^{9}$ in their study also found hypothyroidism associated with increased ALT levels. Chung et al also found ALT levels increased in hypothyroid subjects compared with normal controls $^{10}$. But in another study, Gow et $\mathrm{al}^{11}$ have shown higher activities of ALT when patients with spontaneous primary hypothyroidism are given oral doses of thyroxine. In their study on prepubertal and adolescent beta-thalassemic hypothyroid patients with iron overload, De Sanctis et al ${ }^{12}$ have shown that TSH peak values correlated directly with ALT. In some studies increased ALT activity has been found also in hyperthyroidism ${ }^{13,14}$.

In our study we found ALT activity significantly increased in hypothyroid subjects compared to euthyroid controls, which is consistent with some other studies. In some studies A LT levels were found increased when spontaneous primary hypothyroidism was treated with thyroxine. Increased ALT activity has also been found in hyperthyroidism. All these inconsistent causes behind increased ALT activity force us to draw inference that metabolic derangement due to dysthyroidism might be the cause of increased ALT activity. But how this metabolic derangement causes increased ALT activity is not clear. It can only be postulated that because of abnormal thyroid hormone levels there may be derangement of biochemical reactions within the hepatic cells leading to either increased synthesis of hepatic enzymes or increased permeability of hepatic cell membranes or both. However, more studies with larger number of subjects in different settings and research at the basic molecular level are recommended to explore the basic mechanism of high ALT activity in thyroid derangements.

\section{REFERENCES}

1. Greenspan FS. The thyroid gland. In: Greenspan FS \& Gardner DG (eds). Basic \& Clinical Endocrinology. $7^{\text {th }}$ edn. N ew York: The M cGraw-Hill Companies, 2004: 215-94.

2. Liberopoulos EN, Elisaf M S. Dyslipidemia in patients with thyroid disorders. [On-line] Available from: http://www.endocrinesociety.gr/hormones/pdf/4 2002/05 liberopoul os.pdf, G reece: M oses S Elisaf, 2002.

3. Duntas LH. Thyroid disease and lipids. Thyroid 2002; 12: 287-93.

4. Strachan M WJ, Walker BR. Endocrine disease. In: NA B oon, NR Colledge \& BR Walker (eds). Davidson's principles and practice of medicine. $20^{\text {th }}$ edn. London: Churchill Livingstone, 2006: 739-804.

5. Sawin CT, Castelli W P, Hershman JM, M CN amara P, Bacharach P. The aging thyroid: thyroid deficiency in the Framingham study. A rch Intern M ed 1985; 145: 1386-88.

6. K venty J, Heldgaard PE, B ladbjerg EM, Gram J. Subclinical hypothyroidism is associated with a low grade inflammation, increased triglyceride levels and predicts vascular disease in males below 50 years. Clin Endocrinol 2004; 61(2): 232-38.

7. Ohkubo K, Ihara K, Ohga S, Ishimura M, Hara T. Hypothyroidism and levothyroxine-responsive liver dysfunction in a patient with ring chromosome 18 syndrome. Thyroid 2012; 22(10): 108083.

8. Targher G, M ontagana M, Salvagno G, M oghetti P, M uggeo M, Lippi G. A ssocation between serum TSH, free T4 and serum liver enzyme activities in a large cohort of unselected outpatients. Clin Endocrinol (Oxf) 2008; 68(3): 48184.

9. Goncales J unior FL, Stucchi RS, Papaiordanou PM , Pavan M H, Goncales NS, Pinho J R. Elevated alanine aminotransferase (ALT) in blood donors: an assessment of the main associated conditions and its relationship to the development of hepatitis $\mathrm{C}$. Rev Inst M ed Trop Sao Paulo 1998; 40(4): 21924.

10. Chung GE, Kim D, Kim W, Y im JY, Park MJ, Kim Y J et al. Non-alcoholic fatty liver disease across the spectrum of hypothyroidism. J Hepatol 2012; 57(1): 1506 .

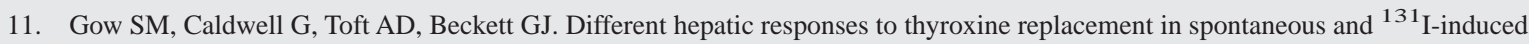
primary hypothyroidism. Clinical Endocrinology 1989; 30(5): 50512.

12. De Sanctis V, Tanas R, Gamberini M R, Sprocati M, Govoni M R, M arsella M . Exaggerated TSH response to TRH ("subbiochemical" hypothyroidism) in prepubertal and adolescent thalassaemic patients with iron overload: prevalence and 20-year natural history. Pediatr Endocrinol Rev. 2008; 9(Suppl 1): 170173.

13. M essarah M, B oumendjel A, Chouabia A, K libet F, A bdennour C, B oulakoud M S et al. Influence of thyroid dysfunction on liver lipid peroxidation and antioxidant status in experimental rats. Exp Toxicol Pathol 2010; 62(3): 301-10.

14. Huang MJ, Li KL, Wel JS, Wu SS, Fan KD, Liaw YF. Sequential liver and bone biochemical changes in hyperthyroidism: prospective controlled follow-up study. A m J Gastroenterol 1994; 89(7): 1071-6. 